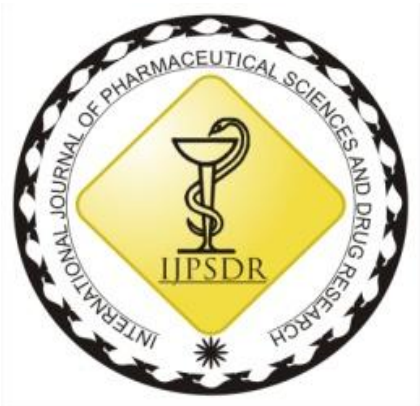

ISSN: 0975-248X

RESEARCH ARTICLE CODEN (USA): IJPSPP

$(\mathrm{cc})$ EY-NG-SA

\title{
Antipsychotic Prescribing Pattern in Elderly Patients with Psychiatric Disorders
}

\author{
Grace Ann Varghese*, K Mansekhar, S Chethana, S Disha Rani, G Roop Sai
}

Seven Hills College of Pharmacy, Tirupati, Andhra Pradesh, India

Copyright (C) 2019 Grace Ann Varghese et al. This is an open access article distributed under the terms of the Creative Commons AttributionNonCommercial-ShareAlike 4.0 International License which allows others to remix, tweak, and build upon the work non-commercially, as long as the author is credited and the new creations are licensed under the identical terms.

\begin{abstract}
The elderly people are more prone to develop psychiatric disorders due to a number of factors like changes in the brain, other illnesses etc. They represent the most vulnerable group as they are most sensitive to the effects of drugs and are at increased risk of developing adverse drug reactions. This warrants the need to make the prescribers cautious about rational prescribing of antipsychotics to the Elderly. The study included elderly inpatients and outpatients visiting psychiatry ward with psychiatric disorders. Descriptive weighed analysis was performed to determine the prescribing practices of atypical antipsychotics. Among the 70 patients who were involved in the study, 36 patients were diagnosed with neurotic disorders and 30 patients were diagnosed with psychotic disorders and 4 were diagnosed with degenerative disorders (dementia). In our study neurotic disorders (51\%) were the major diagnosis. 6 different atypical antipsychotic drugs were prescribed to the patients suffering from different psychiatric disorders. Among them olanzapine (43\%) was the most commonly prescribed drug, followed by quetiapine $(30 \%)$, risperidone $(21 \%)$, clozapine $(3.2 \%)$, lurasidone $(1 \%)$, and aripiprazole $(1 \%)$. This study has concluded that atypical antipsychotics are preferred over typical antipsychotics and Olanzapine is the most commonly prescribed drug for the elderly patients suffering from psychiatric disorders. On comparison of the prescribed daily doses with the maximum daily dose we have observed that the prescribed daily doses for the elderly patients were well within the maximum daily dose of the drugs and in our study no adverse drug reactions were reported in the study subjects that were involved.
\end{abstract}

Keywords: Antipsychotics, prescribing patterns, elderly patients, psychiatric disorders, atypical antipsychotics.

*Corresponding author: Dr. Grace Ann Varghese

Address: Kollamkudy House, Kaippattoor, Kalady PO, Ernakulam-683574, Kerala, India

Tel.: +91-7845166212

E-mail $\bowtie$ : graceannvarghese@gmail.com

Relevant conflicts of interest/financial disclosures: The authors declare that the research was conducted in the absence of any commercial or financial relationships that could be construed as a potential conflict of interest.

Received: 17 June, 2019; Revised: 18 July, 2019; Accepted: 20 July, 2019; Published: 30 July, 2019

\section{INTRODUCTION}

The rapidly expanding field of psychopharmacology is challenging the traditional concepts of psychiatric treatments, and research is constantly seeking new and improved drugs to treat psychiatric disorders. In this way psychiatrists are continuously exposed to newly introduced drugs that are claimed to be more efficacious.

Medicines are an integral part of the healthcare, and modern healthcare is very much dependent on the availability of necessary medicines. They not only save lives and promote health, but also prevent epidemics 
and diseases. Accessibility to medicines is a fundamental right of every person. [1] To bring optimal benefit, they should be safe, efficacious, cost effective and rational. Rational use of medicines plays an important role in the efficacy and sufficiency of therapeutic interventions. [2]

India as the second most populous country in the world has 76.6 million people at or over the age of 60 , constituting about $7.7 \%$ of the total population. The problems faced by this segment of the population are numerous owing to the social and cultural changes that take place within the Indian society. [3]

Drug utilization study has been defined by the World Health Organization (WHO) as "The marketing, distribution, prescription and uses of drugs in a society with special emphasis on the resulting medical, social and economical consequences." The principle aim of the drug utilization research is to facilitate the rational use of the drugs. Without the knowledge of how the drugs are being prescribed, it is difficult to suggest the measures to improve prescribing habits. [4]

Retrospective drug utilization review can be used to identify problems in prescribing patterns through the analysis and interpretation of aggregate archival data on drug prescriptions. An important contribution of retrospective database studies is that they can identify associations between treatment selection and outcomes in the context of patient and prescriber behaviour. [5-6] Antipsychotic prescription patterns are fundamentally different across countries and even regions due to variations in factors including healthcare policies, availability and cost of drugs. Although psychotropic drugs have had a remarkable impact in psychiatry, their utilization in actual clinical practice, effectiveness and safety in the real-life situation needs a continuous study. The prescribing habits of the individual physician are quite stable, and changes usually occur slowly and as a result of various influences, including scientific papers, specialist recommendations, meetings, colleagues, patients, and drug companies. [7]

Prescription pattern monitoring studies are drug utilization studies with the main focus on prescribing, dispensing and administering of drugs. They promote appropriate use of monitored drugs and reduction of abuse or misuse of monitored drugs. Prescription pattern monitoring studies also guide and support prescribers, dispensers and the general public on appropriate use of drugs, collaborate and develop working relationship with other key organizations to achieve a rational use of drugs. Prescription Patterns explain the extent and profile of drug use, trends, quality of drugs, and compliance with regional, state or national guidelines like standard treatment guidelines, usage of drugs from essential medicine list and use of generic drugs. [8] There is increasing importance of Prescription pattern monitoring studies because of a boost in marketing of new drugs, variations in pattern of prescribing and consumption of drugs, growing concern about delayed adverse effects, cost of drugs and volume of prescription. [9]

According to the WHO (1985), the definition of rational use of medicines - "Patients receive medications appropriate to their clinical needs, in doses that meet their own individual requirements, for an adequate period of time, and at the lowest cost to them and their community". [10-11]

The pharmaceutical advantage of the study in the current scenario is that this study will clearly identify the prescription pattern of psychotropic drugs in the Elderly which would enhance our understanding about the psychotropic drugs that work well in geriatric population. The study will also find out whether the prescribed daily dose of the drugs is within the maximum daily dose, thereby avoiding adverse drug reactions due to dosing errors.

The elderly people are more prone to develop psychiatric disorders due to a number of factors like changes in the brain, other illnesses etc. Geriatric patients represent the most vulnerable group as they are most sensitive to the effects of drugs and are at increased risk of developing adverse drug reactions. This warrants the need to make the prescribers cautious about rational prescribing of antipsychotics to the Elderly.

This study aims to analyse the prescribing pattern of antipsychotic drugs in elderly patients with psychiatric disorders in a tertiary care hospital, Tirupati. The objectives of the proposed work is study the current prescribing trend of antipsychotic drugs among patients with psychiatric disorders and to analyse the difference between prescribed daily dose and maximum daily dose.

\section{MATERIALS AND METHODS}

\section{Study design and data collection}

Our study is a retrospective observational study which was conducted in the department of Psychiatry, Sree Venkateshwara Institute of Medical Sciences- SPMCW, Tirupati, Andhra Pradesh.

A detailed data collection form with the patient demographic details, diagnosis and treatment chart was made. Patients who came to the inpatient and outpatient psychiatry department were included in the study based on the inclusion and exclusion criteria. Patient demographic details, diagnosis and treatment chart was collected retrospectively for a period of 6 months. All the data collected through the data collected were subjected to statistical analysis.

Study Design: Retrospective observational study

Study Site: Department of psychiatry, SVIMS-SPMCW, Tirupati

Duration of the Study: 6 months

Sample Size: 70 prescriptions

\section{Inclusion Criteria}

All the patients visiting psychiatry outpatient and inpatient ward with age group of above 60 years with

Int. J. Pharm. Sci. Drug Res. July-August, 2019, Vol 11, Issue 4 (120-125) 
psychiatric disorders and prescribed with antipsychotic drugs.

Exclusion Criteria

Patients of age group below 60 years are excluded.

Study Materials

Data collection form

\section{Institutional Ethical Clearance}

The study protocol along with patient data collection form and informed consent form were submitted to the institutional ethical committee of Sri Venkateswara Institute Of Medical Sciences, SPMC (W)-Tirupati, a 1500 bedded tertiary care hospital for the approval. The study was approved by the institutional ethical committee held on 28 November 2017.

\section{Statistical Analysis}

The collected data was initially entered in to Microsoft excel spreadsheet then it is transferred to SPSS 20.0.The major analytical method to find the significance of the $p$ value is paired student $t$ test. The different variables from the obtained data such as gender, age, diagnosis were collected and analyzed using paired student $t$ test. The obtained results were presented in tabular and graphical form using Microsoft word and excel.

\section{RESULTS}

\section{Patient distribution based on gender}

A retrospective study conducted on antipsychotic prescribing patterns in elderly patients with psychiatric disorders. In this study 70 patients were included. Among the 70 patients $26(37 \%)$ were females and 44 $(63 \%)$ were males.

Patient distribution based on type of psychiatric disorders

A research study was conducted on 70 patients in the psychiatric department of SPWMC-SVIMS. Among them $36(51 \%)$ patients were diagnosed as neurotic disorders, $30(43 \%)$ patients were diagnosed as psychotic disorders and $4(6 \%)$ were diagnosed with other psychiatric disorders (degenerative disorders).

Patients with neurotic disorders

In our study among 70 patients 36 patients were diagnosed with neurotic disorders. Among them 17 $(47 \%)$ of the patients were diagnosed as depressive disorders which are identified as most commonly occurring neurotic disorders, 12 (34\%) patients were diagnosed as anxiety disorders, $3(8 \%)$ patients were diagnosed as panic disorder and OCD was diagnosed in $3(8 \%)$ prescriptions. Incidence of other neurotic disorders like anxiety with depression were very less when compared to the others occupying 3\% in the total number of neurotic disorders.

\section{Patients with psychotic disorders}

Among 70 patients 30 patients were diagnosed as psychotic disorders. Among them $13(43 \%)$ of the patients were diagnosed as psychosis which is identified as most commonly occurring psychotic disorders. 12 patients $(40 \%)$ were diagnosed with Bipolar disorders, and Schizophrenia was diagnosed in
3 patients $(10 \%)$, Depression with psychosis was diagnosed in 2 prescriptions $(7 \%)$.

Percentage of patients based on gender

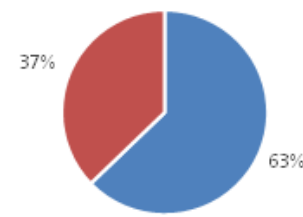

- males =females

Fig. 1: Patients distribution based on gender

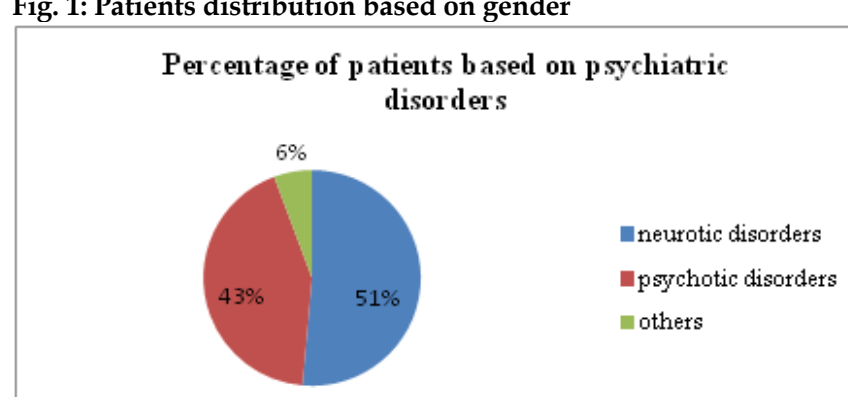

Fig. 2: Percentage of patients based on psychiatric disorders

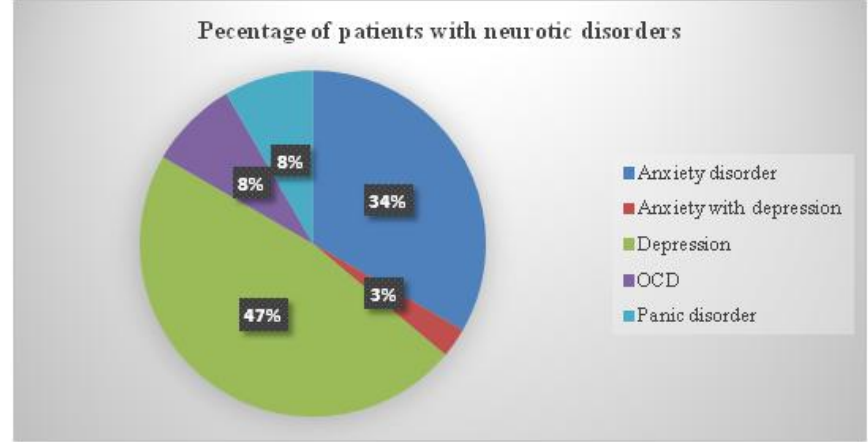

Fig. 3: Percentage of patients with neurotic disorders

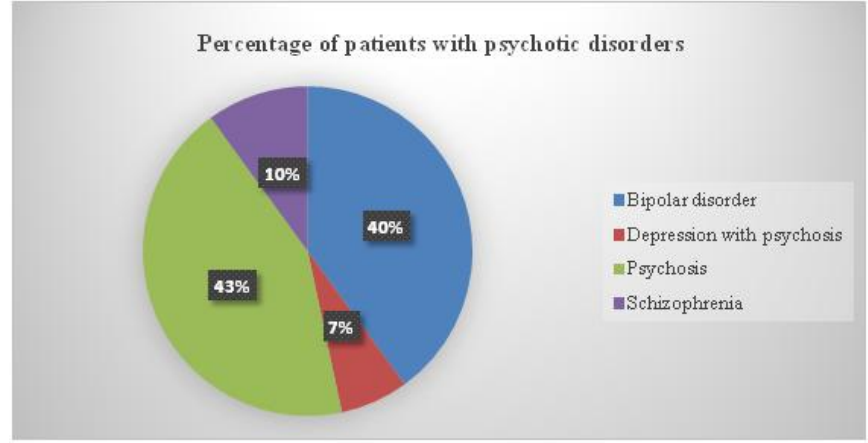

Fig. 4: Percentage of patients with psychotic disorders

Patients with other psychiatric disorders

In 70 patients 4 were diagnosed with degenerative disorder (Dementia).

Type of anti-psychotics prescribed in neurotic disorders

Atypical anti-psychotics were prescribed in neurotic disorders. In our study only atypical anti psychotics were prescribed in neurotic disorders. Among 36 prescriptions olanzapine was most commonly prescribed in 24 prescriptions and risperidone was less commonly prescribed drug. 
Table 1: Type of anti-psychotics prescribed in neurotic disorders

\begin{tabular}{lccccccc}
\hline & & \multicolumn{6}{c}{ Neurotic disorders } \\
\cline { 3 - 8 } S. & Drugs & $\begin{array}{c}\text { Anxie } \\
\text { ty } \\
\text { disor } \\
\text { o }\end{array}$ & $\begin{array}{c}\text { Anxiety } \\
\text { with } \\
\text { depress } \\
\text { ion }\end{array}$ & $\begin{array}{c}\text { Depress } \\
\text { ion }\end{array}$ & $\begin{array}{c}\text { OC } \\
\text { D }\end{array}$ & $\begin{array}{c}\text { Panic } \\
\text { disor } \\
\text { der }\end{array}$ & $\begin{array}{c}\text { Tot } \\
\text { al }\end{array}$ \\
\hline 1. & $\begin{array}{c}\text { Risperid } \\
\text { one }\end{array}$ & 1 & 0 & 0 & 0 & 0 & 1 \\
2 & $\begin{array}{c}\text { Olanzap } \\
\text { ine }\end{array}$ & 9 & 0 & 12 & 3 & 0 & 24 \\
3 & $\begin{array}{c}\text { Quetiapi } \\
\text { ne }\end{array}$ & 4 & 1 & 10 & 0 & 3 & 18 \\
& Total & $\mathbf{1 4}$ & $\mathbf{1}$ & $\mathbf{2 2}$ & $\mathbf{3}$ & $\mathbf{3}$ & $\mathbf{4 3}$ \\
\hline
\end{tabular}

Drug class duplication therapy in different neurotic disorders

In our study the same class of antipsychotics (atypical anti psychotics) were prescribed in 8 prescriptions.

Table 2: Drug Class Duplication Therapy in Different Neurotic Disorders

\begin{tabular}{ccccc}
\hline $\begin{array}{c}\text { S. } \\
\text { No }\end{array}$ & Disease & $\begin{array}{c}\text { One atypical } \\
\text { antipsychotic } \\
\text { drug }\end{array}$ & $\begin{array}{c}\text { Two } \\
\text { atypical } \\
\text { antipsychot } \\
\text { ic drugs }\end{array}$ & $\begin{array}{c}\text { Multiple } \\
\text { atypical } \\
\text { antipsychotic } \\
\text { drugs }\end{array}$ \\
\hline 1. & $\begin{array}{c}\text { Anxiety } \\
\text { disorder }\end{array}$ & 10 & 2 & 0 \\
2. & $\begin{array}{c}\text { Anxiety } \\
\text { with } \\
\text { depression }\end{array}$ & 1 & 0 & 0 \\
3. & $\begin{array}{c}\text { Depression } \\
\text { OCD }\end{array}$ & 11 & 6 & 0 \\
4. & 3 & 0 & 0 \\
5. & $\begin{array}{c}\text { Panic } \\
\text { disorder }\end{array}$ & 3 & 0 & 0 \\
\hline
\end{tabular}

Type of anti-psychotics prescribed in psychotic disorders

Atypical anti-psychotics were prescribed in psychotic disorders. Among the 70 study subjects that were involved 30 were diagnosed with psychotic disorders. In those 30 prescriptions risperidone was the most commonly prescribed antipsychotic. Lurasidone was the least commonly prescribed antipsychotic.

Table 3: Type of anti-psychotics prescribed in psychotic disorders

\begin{tabular}{ccccccc}
\hline & & \multicolumn{4}{c}{ Psychotic Disorders } & \\
\cline { 3 - 6 } S. & Drugs & $\begin{array}{c}\text { Bipolar } \\
\text { disorder }\end{array}$ & $\begin{array}{c}\text { Depression } \\
\text { with } \\
\text { psychosis }\end{array}$ & $\begin{array}{c}\text { Psychos } \\
\text { is }\end{array}$ & Schizophrenia & Total \\
\hline 1. & Risperidone & 5 & 1 & 12 & 0 & 18 \\
2. & Lurasidone & 0 & 0 & 1 & 0 & 1 \\
3. & Olanzapine & 4 & 1 & 7 & 3 & 15 \\
4. & Quetiapine & 4 & 1 & 2 & 0 & 7 \\
5. & Clozapine & 3 & 0 & 0 & 0 & 3 \\
& Total & $\mathbf{1 6}$ & $\mathbf{3}$ & $\mathbf{2 2}$ & $\mathbf{3}$ & $\mathbf{4 4}$ \\
\hline
\end{tabular}

Table 4: Drug class duplication therapy in different psychotic disorders

\begin{tabular}{ccccc}
\hline $\begin{array}{c}\text { S. } \\
\text { No. }\end{array}$ & Disorder & $\begin{array}{c}\text { One atypical } \\
\text { antipsychotic } \\
\text { drug }\end{array}$ & $\begin{array}{c}\text { Two atypical } \\
\text { antipsychotic } \\
\text { drugs }\end{array}$ & $\begin{array}{c}\text { Multiple } \\
\text { atypical } \\
\text { antipsychotic } \\
\text { drugs }\end{array}$ \\
\hline 1. & $\begin{array}{c}\text { Bipolar } \\
\text { disorder }\end{array}$ & 8 & 4 & 0 \\
Depression & & 1 & 1 & 0 \\
with & $\begin{array}{c}\text { with } \\
\text { psychosis }\end{array}$ & 5 & 7 & 1 \\
4. & $\begin{array}{c}\text { Psychosis } \\
\text { Schizophrenia }\end{array}$ & 3 & 0 & 0 \\
\hline
\end{tabular}

Drug class duplication therapy in different psychotic disorders

In our study the same class of antipsychotics (atypical antipsychotics) were prescribed in 13 prescriptions.

Type of anti-psychotics prescribed in other psychiatric disorders

Atypical anti-psychotics were prescribed in psychotic disorders (dementia). Among 70 patients 4 were diagnosed as degenerative disorder (dementia). In these 4 cases quetiapine was the most commonly prescribed drug.

Table 5: Type of anti-psychotics prescribed in other psychiatric disorders

\begin{tabular}{ccc}
\hline S. No. & Drugs & Dementia \\
\hline 1. & Quetiapine & 3 \\
2. & Risperidone & 1 \\
3. & Aripiprazole & 1 \\
4. & Olanzapine & 1 \\
\hline
\end{tabular}

Type of anti-psychotics prescribed in psychiatric disorders

In our study 6 different atypical antipsychotics were prescribed to the patients to treat the respective disease conditions, among them Olanzapine was the most commonly prescribed drug (43\%), followed by Quetiapine (30\%), Risperidone (21\%), Clozapine (3.2\%), Lurasidone (1\%), Aripiprazole (1\%).

Table 6: Type of anti-psychotics prescribed in psychiatric disorders

\begin{tabular}{cccc}
\hline S. No. & Drugs & $\begin{array}{c}\text { Prescribed in } \\
\text { number of cases }\end{array}$ & $\begin{array}{c}\text { Frequency of } \\
\text { prescription }\end{array}$ \\
\hline 1. & Risperidone & 20 & $21 \%$ \\
2. & Olanzapine & 40 & $43 \%$ \\
3. & Quetiapine & 28 & $30 \%$ \\
4. & Lurasidone & 1 & $1 \%$ \\
5. & Aripiprazole & 1 & $1 \%$ \\
6. & Clozapine & 3 & $3.2 \%$ \\
& Total & 93 & $100 \%$ \\
\hline
\end{tabular}

\section{Doses of Prescribed Antipsychotics}

The maximum daily dose and prescribed daily dose of antipsychotic drugs that were involved in the study were listed below

Table 7: Comparison of maximum daily dose with prescribed daily dose

\begin{tabular}{cccc}
\hline $\begin{array}{c}\text { S. } \\
\text { No. }\end{array}$ & Drugs & $\begin{array}{c}\text { Maximum daily } \\
\text { dose }\end{array}$ & $\begin{array}{c}\text { Prescribed daily } \\
\text { dose }\end{array}$ \\
\hline 1. & Risperidone & $16 \mathrm{mg} /$ day & $2-4 \mathrm{mg} /$ day \\
2. & Olanzapine & $20 \mathrm{mg} /$ day & $5-10 \mathrm{mg} /$ day \\
3. & Quetiapine & $800 \mathrm{mg} /$ day & $50-200 \mathrm{mg} /$ day \\
4. & Lurasidone & $80 \mathrm{mg} /$ day & $40 \mathrm{mg} /$ day \\
5. & Aripiprazole & $30 \mathrm{mg} /$ day & $2.5 \mathrm{mg} /$ day \\
6. & Clozapine & $900 \mathrm{mg} /$ day & $25 \mathrm{mg} /$ day \\
\hline
\end{tabular}

Among the prescribed drugs no case was found with prescribed daily dose given more than maximum daily dose. This prescription pattern had no ADR in the study subjects as drug doses were well within the maximum dose.

\section{Adverse Drug Reactions}


A retrospective study was conducted on antipsychotic prescribing patterns in elderly patients with psychiatric disorders; there were no significant adverse drug reactions among the 70 prescriptions of elderly patients that were involved in the study.

\section{DISCUSSION}

The treatment options for psychiatric disorders mainly involve antipsychotic drugs. They are divided into 2 classes based on their pharmacological actions. The usage of atypical antipsychotics (new generation) has increased day by day as they show less extrapyramidal symptoms and less ADR compared to typical (first generation) antipsychotics.

In our study a total of 70 patients were involved, out of which $63 \%$ were males and $37 \%$ were females indicating males are more prone to psychiatric disorders in elderly patients than females.

In our study patients were categorized into 3 groups based on their diagnosis that include patients suffering from neurotic disorders, psychotic disorders and other psychiatric disorders (degenerative disorders). Among them patients suffering from neurotic disorders (51\%) were more when compared to the psychotic disorders $(43 \%)$ stating that patients suffering from neurotic disorders were more common in elderly patients with psychiatric disorders.

In our study among the 70 patients involved, olanzapine $(43 \%)$ was found to be the most commonly prescribed antipsychotic drug followed by quetiapine $(30 \%)$ for the patients suffering from psychiatric disorders.

But when neurotic and psychotic disorders were taken separately,

In neurotic disorders - olanzapine was prescribed in 24 cases out of 43 cases, which was eventually found to be the most commonly prescribed drug for elderly patients and it was followed by quetiapine that was prescribed in 18 cases.

In psychotic disorders - risperidone was found to be the most commonly prescribed antipsychotic for elderly patients, out of 49 cases of psychotic disorders 18 were prescribed and it was followed by olanzapine that was prescribed in 15 cases.

Shankar kumar et al ${ }^{[12]}$ has conducted a study similar to this in the region of Delhi and they stated that out of 293 antipsychotics prescribed, risperidone has been the most commonly prescribed antipsychotic (44.71\%) followed by olanzapine (34.81\%) and aripiprazole (7.12\%). In our study done with elderly patients we found that olanzapine $(43 \%)$ was the most commonly prescribed drug followed by quetiapine (30\%) and risperidone $(21 \%)$. It is indicating that the age is one of the factors where the choice of the drug depends especially in elderly patients.

Studies conducted by Usharani H Patted et al., [13] showed that olanzapine was the most commonly prescribed atypical antipsychotic $48.6 \%$ followed by risperidone $45.8 \%$. In the present study the common antipsychotics prescribed were olanzapine (43\%) followed by Quetiapine (30\%). Similar observations were made by Rode SB et al., [14] where $65.34 \%$ patients received atypical antipsychotics and olanzapine $(45.13 \%)$ was the most common antipsychotic prescribed. Paul et al., [15] study also showed that olanzapine $(51.04 \%)$ was most commonly prescribed followed by risperidone $(17.14 \%)$.

The study conducted by Roopadevi et al., [16] has showed that out of 405 prescriptions containing 838 drugs, risperidone (48.9) and olanzapine (29.3\%) were the most commonly prescribed atypical antipsychotics. Among typical antipsychotics, chlorpromazine (6.5\%), fluphenazine $(2.2 \%)$ and haloperidol (1.1\%) were prescribed. In our study out of 70 prescriptions there were no typical antipsychotics prescribed, comparing to this study the usage of typical antipsychotics was very minimal or none of them were prescribed in elderly patients as like in our study, reflecting that atypical antipsychotics were prescribed over typical antipsychotics because of their treatment efficacy, better tolerability and reduced risk of EPS.

Piparva KG et al., ${ }^{[17]}$ had done astudy on the analysis of adverse drug reactions of atypical anti psychotic drugs and in their study they found that the gastro intestinal and sleep disturbances were more frequently observed in the initial course of treatment (within 7 days to 2-3 months after treatment) adverse drug reactions caused by the olanzapine were found with the dose range of $10-15 \mathrm{mg} /$ day and a single case of perioral tremor occurred at a dose of $20 \mathrm{mg} /$ day. In our study which was done only in elderly patients, olanzapine was usually prescribed at the dose of $5-10 \mathrm{mg} /$ day. The prescribed dose was well within the maximum daily dose (20 mg/day) and we had not found any adverse drug reactions in the study subjects for the olanzapine drug.

In their study, adverse drug reactions were also observed for the drug risperidone, gastrointestinal sleep disturbance was observed in the initial (within 7 days to 2-3 months after treatment) stages of the treatment, while EPS, fatigue, seizures and dizziness were observed after long-term (3-9 months) use. All ADR's with risperidone were observed at the therapeutic dose (4 mg/day) except EPS, seizure and hypersalivation that occurred at the dose of $6 \mathrm{mg} /$ day. In our study also risperidone was usually prescribed at the daily dose of 2-4 $\mathrm{mg}$ but no adverse drug reactions were identified in the 20 cases in which it was prescribed.

In the study done by Robert L. Findling et al., [18] they observed that the quetiapine was flexibly dosed at 400$800 \mathrm{mg} /$ day. In their study the most common AE's reported were somnolence, headache, sedation, weight increase and vomiting. They also stated that special monitoring of lipid profiles should be done as there were significant alterations in their lipid profiles and weight gain was also seen significantly in $18.3 \%$ of 
patients. Their clinical study data suggested that weight gain was frequent among the youth treated with agents in the atypical antipsychotic class and that youth are more vulnerable than adults to this weight gain. In our study quetiapine was prescribed with the dose of 50-200 $\mathrm{mg} /$ day which was well within the maximum daily dose and also the dosing range prescribed in the above study. As our study was done in elderly patients we observed that the dosing of the quetiapine was given in minimal range and no adverse events or adverse drug reactions were identified in the subjects involved in the study.

In our study the age group of the patients was above 60 years and it was a retrospective study which was carried out over the past 6 months. In the study subjects involved males were more prone to psychiatric disorders than females with $63 \%$ and $37 \%$ respectively. Among the psychiatric disorders, patients suffering from neurotic disorders were in more number than the psychotic disorders. In our study we have concluded that the olanzapine (43\%) was the most commonly prescribed drug for the elderly patients suffering from psychiatric disorders followed by quetiapine (30\%) and risperidone $(21 \%)$. On comparison of the prescribed daily doses with the maximum daily dose we have observed that the prescribed daily doses for the elderly patients were well within the maximum daily dose of the drugs and in our study no adverse drug reactions were reported in the study subjects that were involved.

\section{ACKNOWLEDGEMENT}

We express our sincere thanks and gratitude from the bottom of our heart to all those who directly and indirectly helped in the successful completion of this research.

\section{REFERENCES}

1. Kar SS, Pardhan HS, Mohanta GP. Concept of essential medicine and rational use of public health. Indian Journal of Community Medicine. 2010; 35(1): 10-3.

2. World Health Organisation (WHO). Expert Committee. Geneva: WHO; 1977. Report of a WHO 1977. The Selection of Essential Drugs; PP: 7-35. WHO Technical Report Series, No.615.

3. Dilip C, Dinesh KMK, Divya R, Lisa MM. Prescription Monitoring Study of Antipsychotic Drugs in Geriatric
Population at Tertiary Level Referral Hospital in Rural India. Indian Journal of Pharmacy Practice. 2012; 5(3):49-52.

4. Piparva KG, Parmar DM, Singh AP, Gajera MV, Trivedi HR. Drug utilization study of psychotropic drugs in outdoor patients in a teaching hospital. Indian J Psychol Med. 2011;33(1):54-8.

5. Deshmukh SA, Shaikh TS. Evaluation of psychotropic drugs use pattern among out patients attending psychiatry department at government medical college and hospital, Nagpur: A cross sectional study. Int J Pharm Bio Sci. 2012;3(3):428-36.

6. Sheldon TA. Problems of using modeling in the economic evaluation of health care. Health Econ 1996;5:1-11.

7. Pradhan SC, Shewade DG, Shashindran CH, Bapna JS. Drug utilization studies. National Med J India. 1988;1:185-189.

8. Vijaykumar TM, Sathyavati D, Subhashini T, Grandhi S, Dhanaraju MD. Assessment of prescribing patterns/trends and rationality of drug prescribing. International Journal of pharmacology, 2011; 7(1): 140-143.

9. Bjerrum L, Larsen J, Søndergaard J. [Drug prescription patterns in general practice. Extent, problems and possibilities of improvement]. Ugeskr Laeger. 2002 Nov 4;164(45):5273-7.

10. World Health Organization. Promoting rational use of medicines: core components - WHO policy perspectives on medicines. 2002.

11. WHO Model Formulary. Geneva: WHO press; 2004.

12. Kumar S, Chawla S, Bimba HV, Rana P, Dutta S, Kumar S. Analysis of Prescribing Pattern and Techniques of Switching Over of Antipsychotics in Outpatients of A Tertiary Care Hospital in Delhi: A Prospective, Observational Study. J Basic Clin Pharma 2017; 8: 178-184.

13. Patted UH, Hema NG, Nagaraj AKM. Antipsychotics in schizophrenia: a retrospective study of drug utilization pattern in outpatient department of psychiatry at a tertiary care hospital. Int J Basic Clin Pharmacol 2018; 7: 167-72.

14. Rode SB, Salankar HV, Verma PR, Sinha U, Ajagallay RK. Pharmacoepidemiological survey of schizophrenia in Central India. Int J Res Med Sci. 2014; 2: 1058-62.

15. Paul PK, Konwar M, Das S. Prescribing pattern of antipsychotic drugs in a tertiary care hospital of Assam. International Journal of Pharmacy and Pharmaceutical Sciences. 2014; 6(4): 435-437.

16. Roopadevi HS, Nagabushan K, Ramesh KN. Pattern of Psychotropic prescription in a tertiary care hospital: A critical analysis. Asian Journal of Pharmaceutical and Clinical research. 2015; 8(5): 252-255.

17. Piparva KG, Parmar DM, Singh AP, Gajera MV, Trivedi HR. Drug utilization study of psychotropic drugs in outdoor patients in a teaching hospital. Indian J Psychol Med. 2011 Jan;33(1):54-8.

18. Findling RL, Pathak S, Earley WR, Liu S, DelBello M. Safety, tolerability, and efficacy of quetiapine in youth with schizophrenia or bipolar I disorder: A 26-week,open-label, continuation study. J. Child Adolesc. Psychopharmacol. 2013; 23:490-501.

HOW TO CITE THIS ARTICLE: Varghese GA, Mansekhar K, Chethana S, Disha Rani S, Roop Sai G. Antipsychotic Prescribing Pattern in Elderly Patients with Psychiatric Disorders. Int. J. Pharm. Sci. Drug Res. 2019; 11(4): 120-125. DOI: 10.25004/IJPSDR.2019.110403 